\title{
Preoperative proteinuria predicts acute kidney injury in patients undergoing cardiac surgery
}

\author{
Steven G. Coca, DO, MS, ${ }^{\text {a,b }}$ Divakar Jammalamadaka, MD, ${ }^{a}$ Kyaw Sint, MPH, ${ }^{\text {a,b }}$ \\ Heather Thiessen Philbrook, MMath, ${ }^{\mathrm{c}}$ Michael G. Shlipak, MD, ${ }^{\mathrm{d}, \mathrm{e}}$ Michael Zappitelli, MD, MSc, ${ }^{\mathrm{f}}$ \\ Prasad Devarajan, MD, ${ }^{\mathrm{g}}$ Sabet Hashim, MD, ${ }^{\mathrm{h}}$ Amit X. Garg, MD, PhD, ${ }^{\mathrm{c}}$ and Chirag R. Parikh, MD, PhD, ${ }^{\mathrm{a}, \mathrm{b}}$ \\ for the Translational Research Investigating Biomarker Endpoints in Acute Kidney Injury Consortium
}

\begin{abstract}
Objective: The study objective was to examine the utility of using proteinuria in preoperative risk stratification for acute kidney injury. Acute kidney injury is a common and important complication for patients undergoing cardiac surgery. Proteinuria, which reflects structural damage to the glomeruli or renal tubules, may aid the prediction of acute kidney injury.
\end{abstract}

\begin{abstract}
Methods: The urine albumin to creatinine ratio and dipstick proteinuria concentration were prospectively measured in 1159 patients undergoing cardiac surgery. The cohort was organized into 4 clinical risk categories based on the preoperative urine albumin to creatinine ratio: $10 \mathrm{mg} / \mathrm{g}$ or less $(\leq 1.1 \mathrm{mg} / \mathrm{mmol}), 11$ to $29 \mathrm{mg} / \mathrm{g}(1.2-3.3$ $\mathrm{mg} / \mathrm{mmol}), 30$ to $299 \mathrm{mg} / \mathrm{g}(3.4-33.8 \mathrm{mg} / \mathrm{mmol})$, and $300 \mathrm{mg} / \mathrm{g}$ or greater $(\geq 33.9 \mathrm{mg} / \mathrm{mmol})$. The primary outcome was postoperative acute kidney injury, defined by the Acute Kidney Injury Network stage I criterion (serum creatinine increase $\geq 50 \%$ or $\geq 0.3 \mathrm{mg} / \mathrm{dL} ; 26.5 \mu \mathrm{mol} / \mathrm{L}$ ).

Results: An increase in the incidence of acute kidney injury was noted across the urine albumin to creatinine ratio categories. Adding the urine albumin to creatinine ratio to the clinical model to predict acute kidney injury improved the area under the curve from 0.67 to $0.70(P<.001)$, and the continuous net reclassification improvement was $29 \%(P<.001)$. The urine albumin to creatinine ratio was also independently associated with the risk of in-hospital dialysis and intensive care unit and hospital lengths of stay. Surgery status and preoperative glomerular filtration rate were effect modifiers; the association was stronger among those undergoing elective surgery and those with an estimated glomerular filtration rate of $45 \mathrm{~mL} / \mathrm{min} / 1.73 \mathrm{~m}^{2}$ or greater.
\end{abstract}

Conclusions: Preoperative proteinuria provides graded stratification risk for acute kidney injury and is an independent predictor of other outcomes in patients undergoing cardiac surgery. ( $\mathrm{J}$ Thorac Cardiovasc Surg 2012;143:495-502)

Acute kidney injury (AKI) is a common and significant complication in patients undergoing cardiac surgery. Postoperatively, AKI is associated with increased hospital length of stay and in-hospital mortality, and those who survive AKI have an increased risk of developing chronic kidney disease. ${ }^{1,2}$ Thus, preoperative prediction of AKI is important in clinical decision making.

\footnotetext{
From the Department of Internal Medicine, ${ }^{\text {a }}$ Yale University School of Medicine, New Haven, Conn; Clinical Epidemiology Research Center, ${ }^{\mathrm{b}}$ VA Connecticut, West Haven, Conn; Division of Nephrology, Department of Medicine, ${ }^{\mathrm{c}}$ University of Western Ontario, London, Ontario, Canada; Department of Medicine, ${ }^{\mathrm{d}}$ San Francisco VA Medical Center, and University of California, San Francisco, Calif; Department of Epidemiology and Biostatistics, ${ }^{\mathrm{e}}$ University of California, San Francisco, Calif; Department of Pediatrics, ${ }^{\mathrm{f}}$ Division of Nephrology, McGill University Health Center, Montreal Children's Hospital, Montreal, Quebec, Canada; Department of Pediatrics, ${ }^{\mathrm{g}}$ Cincinnati Children's Hospital Medical Center, University of Cincinnati College of Medicine, Cincinnati, Ohio; and Department of Surgery, ${ }^{\text {h }}$ Yale University School of Medicine, New Haven, Conn.

The research reported in this article was supported by the American Heart Association Clinical Development award; Grant R01HL-085757 from the National Heart, Lung, and Blood Institute; and CTSA Grant UL1 RR024139 from the National Center for Research Resources.

Disclosures: Dr Devarajan is a consultant to Abbott Diagnostics and Biosite, Inc. All other authors have nothing to disclose with regard to commercial support.
}

One of the most important determinants for the development of AKI in cardiac surgery is preexisting kidney function, usually assessed by estimated glomerular filtration rate (eGFR). ${ }^{3,4}$ However, another dimension that offers a clue to the integrity of the kidney is proteinuria as assessed by the urine albumin to creatinine ratio (UACR) or dipstick proteinuria. ${ }^{5}$ As a reflection of structural damage to the

\footnotetext{
Members of the AKI-TRIBE consortium: Yale-New Haven: Drs Michael Dewar, Umer Darr, Sabet Hashim, Richard Kim, John Elefteriades, Arnar Geirsson, Susan Garwood, Prakash Nadkarni, and Simon Li. Danbury: Dr Cary Passik. London: Drs Michael Chu, Martin Goldbach, Lin Ruo Guo, Bob Kiaii, Neil McKenzie, Mary Lee Myers, Richard Novick, and Mac Quantz. Chicago: Drs Jay Koyner, Patrick Murray, Shahab A. Akhter, Jai Raman, and Valluvan Jeevanandam. Cincinnati: Drs Catherine D. Krawczeski, Michael Bennett, and Qing Ma.

Received for publication May 26, 2011; revisions received Aug 9, 2011; accepted for publication Sept 21, 2011; available ahead of print Nov 4, 2011.

Address for reprints: Chirag R. Parikh, MD, PhD, Section of Nephrology Yale University and VAMC 950 Campbell Ave, Mail Code 151B Bldg 35 A, Room 219, West Haven, CT 06516 (E-mail: chirag.parikh@yale.edu). $0022-5223 / \$ 36.00$

Copyright (C) 2012 by The American Association for Thoracic Surgery doi:10.1016/j.jtcvs.2011.09.023
} 


\section{Abbreviations and Acronyms \\ AKI = acute kidney injury \\ AKIN $=$ Acute Kidney Injury Network \\ $\mathrm{AUC}=$ area under the curve \\ $\mathrm{CABG}=$ coronary artery bypass grafting \\ eGFR $=$ estimated glomerular filtration rate \\ GFR $=$ glomerular filtration rate \\ $\mathrm{UACR}=$ urine albumin to creatinine ratio}

glomeruli or kidney tubules, proteinuria is increasingly recognized as an important measure of kidney disease ${ }^{6}$ and risk factor for the development of AKI. ${ }^{7-10}$ Proteinuria adds prognostic value to the GFR for understanding the risks of AKI,${ }^{9}$ cardiovascular disease, and death. ${ }^{11}$ Urine protein measurements are readily available and inexpensive, and can even be assessed at the bedside using a dipstick.

Several prediction models have been published to predict dialysis (incidence $1 \%-2 \%$ ) after cardiac surgery, but none of these models perform well for prediction of less severe forms of AKI. ${ }^{12,13}$ These risk-assessment tools are used to balance the risks and benefits of cardiac surgery and to monitor the quality of care and outcomes of cardiac surgery by surgeons and hospitals. Because of the intense scrutiny on cardiac surgery outcomes, even mild improvements to help risk adjust for adverse outcomes could have great clinical importance. This may allow clinicians to alter perisurgical approaches to minimize AKI or to consider preventative therapies that prove effective in clinical trials.

Thus, our objective was to examine the utility of urinary albumin concentrations and urine dipstick measures of proteinuria to stratify for the risk of AKI in patients undergoing cardiac surgery.

\section{MATERIALS AND METHODS \\ Design and Setting}

The participants reported are a subset of the Translational Research Investigating Biomarker Endpoints in Acute Kidney Injury (Clinicaltrials. gov NCT00774137) cohort. We prospectively enrolled 1219 patients who were at risk for developing postoperative AKI. The UACR was measured on available preoperative urine samples $(\mathrm{n}=1159)$, and dipstick proteinuria was measured on 1123 samples. Sixty patients did not have the UACR, and their characteristics were similar to those of the rest of the cohort. The cohort included adults undergoing cardiac surgery (coronary artery bypass grafting [CABG], surgery for valve disease, or both) at 6 academic medical centers in North America between July 2007 and December 2009. All patients were at high risk for AKI, defined by the presence of one or more of the following criteria: preexisting renal impairment (baseline serum creatinine $>2 \mathrm{mg} / \mathrm{dL}$ [177 $\mu \mathrm{mol} / \mathrm{L}]$ ), ejection fraction less than $35 \%$ or grade 3 or 4 left ventricular dysfunction, age more than 65 years, diabetes mellitus, concomitant $C A B G$ and valve surgery, or repeat revascularization surgery. Exclusion criteria included prior kidney transplantation, preoperative advanced chronic kidney disease or end-stage renal disease, or administration of nephrotoxic drugs preoperatively.
All participants provided written informed subject consent. Each institution's research ethics board approved the study.

\section{Sample Collection, Biomarker Measurement, and Outcomes}

A fresh urine sample $(10 \mathrm{~mL})$ was collected at the preoperative visit or on the morning of the surgery. The samples were centrifuged at $1000 \mathrm{~g}$ for 10 minutes to remove cellular debris. The supernatant was stored at $-80^{\circ} \mathrm{C}$ in $1-\mathrm{mL}$ aliquots. All urine albumin assays were measured by immunoturbidimetry on a Siemens Dimension Plus with a Heterogeneous Immunoassay clinical analyzer (Siemens Healthcare Diagnostics, Deerfield, Ill), per manufacturer's instructions. Urine creatinine was measured by the modified Jaffe reaction. The cohort was organized into 4 clinical risk categories according to the preoperative UACR: $10 \mathrm{mg} / \mathrm{g}$ or less ( $\leq 1.1 \mathrm{mg} / \mathrm{mmol}), 11$ to $29 \mathrm{mg} / \mathrm{g}(1.2-3.3 \mathrm{mg} / \mathrm{mmol}), 30$ to $299 \mathrm{mg} / \mathrm{g}$ $(3.4-33.8 \mathrm{mg} / \mathrm{mmol})$, and $300 \mathrm{mg} / \mathrm{g}$ or more $(\geq 33.9 \mathrm{mg} / \mathrm{mmol}){ }^{7}$ Urine dipstick was graded as negative, trace, 30 to $99 \mathrm{mg} / \mathrm{dL}(0.03-$ $0.099 \mathrm{~g} / \mathrm{L})$, and $100 \mathrm{mg} / \mathrm{dL}$ or more $(\geq 0.1 \mathrm{~g} / \mathrm{L})$ and measured in the fresh urine using Siemens Clinitek Status ID number SN48923.

The primary outcome was postoperative AKI based on Acute Kidney Injury Network (AKIN) stage I (serum creatinine increase $\geq 50 \%$ or $\geq$ $0.3 \mathrm{mg} / \mathrm{dL}[26.5 \mu \mathrm{mol} / \mathrm{L}]$ from the preoperative value or requirement of dialysis). The secondary outcome was AKI based on AKIN stage II (serum creatinine increase $\geq 100 \%$ or requirement of dialysis).

\section{Statistical Analysis}

Demographics, comorbidities, and procedural variables were collected using definitions of the Society of Thoracic Surgeons (http://www.ctsnet. org/file/rptDataSpecifications252_1_ForVendorsPGS. pdf). Relative risks of AKI for the clinical risk categories, adjusted for variables that were available preoperatively, including demographics, comorbidities, and procedural variables, were calculated by logistic regression with site as a random effect (proc GLIMMIX procedure in SAS 9.2 software, SAS Institute, Cary, NC). Estimated odds ratios were converted and presented as relative risks. ${ }^{14}$ The multivariate clinical model included age (per year), sex, race, preoperative eGFR calculated by Chronic Kidney Disease Epidemiology Collaboration equation, ${ }^{15}$ elective surgery, type of surgery, cardiac catheterization in past 48 hours, and history of diabetes, hypertension, chronic congestive heart failure, or myocardial infarction. These variables have been shown to predict AKI in the cardiac surgery setting by the Society of Thoracic Surgeons. ${ }^{16}$ To evaluate the added effect of UACR on risk discrimination for AKI, we constructed receiver operating characteristic curves and calculated the area under the curve (AUC) for the UACR alone, the multivariate clinical model alone, and with the addition of UACR to the clinical model using R 2.11.0 (R Foundation for Statistical Computing, Vienna, Austria). We tested for a statistically significant increase in the AUC using the method developed by DeLong and colleagues. ${ }^{17}$ We determined the continuous net reclassification improvement as suggested by Pencina and colleagues. ${ }^{18}$ We evaluated for interaction with the likelihood ratio test on the following subgroups: age $(<65,65-75,75-85,>85$ years), diabetes, elective versus urgent surgery, and preoperative stages of eGFR.

\section{RESULTS}

Of 1159 patients with preoperative UACR measurements, the UACR was $10 \mathrm{mg} / \mathrm{g}$ or less in $405(35 \%), 11$ to $29 \mathrm{mg} / \mathrm{g}$ in $355(31 \%), 30$ to $299 \mathrm{mg} / \mathrm{g}$ in $329(28 \%)$, and $300 \mathrm{mg} / \mathrm{g}$ or more in $70(6 \%)$. Characteristics associated with higher levels of albuminuria included older age, diabetes, heart failure, ejection fraction less than $40 \%$, higher preoperative serum creatinine, and lower 
TABLE 1. Preoperative characteristics by albuminuria in adults undergoing cardiac surgery

\begin{tabular}{|c|c|c|c|c|c|}
\hline & $\begin{array}{c}\text { UACR }<10 \mathrm{mg} / \mathrm{g} \\
(\mathrm{n}=\mathbf{4 0 5}, \mathbf{3 5} \%)\end{array}$ & $\begin{array}{l}\text { UACR 11-29 mg/g } \\
(\mathrm{n}=355,31 \%)\end{array}$ & $\begin{array}{c}\text { UACR 30-299 mg/g } \\
(n=329,28 \%)\end{array}$ & $\begin{array}{c}\text { UACR } \geq 300 \mathrm{mg} / \mathrm{g} \\
(\mathrm{n}=\mathbf{7 0 , 6} \%)\end{array}$ & $\begin{array}{l}P \text { value } \\
\text { for trend }\end{array}$ \\
\hline Age (mean, SD) & $70.3(10.4)$ & $71.8(9.7)$ & $73.0(9.7)$ & $70.7(10.6)$ & .003 \\
\hline$<65$ y $(\mathrm{n}, \%)$ & $97(24 \%)$ & $73(21 \%)$ & $61(19 \%)$ & $19(27 \%)$ & \\
\hline $65-75 y$ & $164(40 \%)$ & $135(38 \%)$ & $118(36 \%)$ & $24(34 \%)$ & \\
\hline $75-85 y$ & $134(33 \%)$ & $133(37 \%)$ & $120(36 \%)$ & $23(33 \%)$ & \\
\hline$>85 \mathrm{y}$ & $10(2.5 \%)$ & $14(3.9 \%)$ & $30(9.1 \%)$ & $4(5.7 \%)$ & \\
\hline Male (n, \%) & $288(71 \%)$ & $234(66 \%)$ & $225(68 \%)$ & $40(57 \%)$ & .09 \\
\hline White race $(\mathrm{n}, \%)$ & $384(95 \%)$ & $331(93 \%)$ & $309(94 \%)$ & $60(86 \%)$ & .09 \\
\hline Diabetes $(\mathrm{n}, \%)$ & $141(35 \%)$ & $137(39 \%)$ & $155(47 \%)$ & $46(66 \%)$ & $<.001$ \\
\hline Hypertension (n, \%) & $309(76 \%)$ & $280(79 \%)$ & $266(81 \%)$ & $59(84 \%)$ & .06 \\
\hline Myocardial infarction (n, \%) & $114(29 \%)$ & $83(24 \%)$ & $70(22 \%)$ & $25(36 \%)$ & .33 \\
\hline Heart failure $(\mathrm{n}, \%)$ & $96(24 \%)$ & $77(22 \%)$ & $98(30 \%)$ & $25(36 \%)$ & .01 \\
\hline Ejection fraction $\leq 40 \%(\mathrm{n}, \%)$ & $64(18 \%)$ & $49(15 \%)$ & $84(28 \%)$ & $24(37 \%)$ & $<.001$ \\
\hline \multicolumn{6}{|l|}{ Operative characteristics (n, \%) } \\
\hline Prior cardiac surgery & $55(14 \%)$ & $43(12 \%)$ & $46(14 \%)$ & $5(7 \%)$ & .58 \\
\hline Elective surgery & $306(76 \%)$ & $295(83 \%)$ & $265(81 \%)$ & $54(77 \%)$ & .16 \\
\hline Cardiac catheterization in last $48 \mathrm{~h}$ & $18(4 \%)$ & $18(5 \%)$ & $23(7 \%)$ & $3(4 \%)$ & .24 \\
\hline Surgery $(n, \%)$ & & & & & .01 \\
\hline CABG & $228(56 \%)$ & $148(42 \%)$ & $147(45 \%)$ & $35(50 \%)$ & \\
\hline Valve & $87(21 \%)$ & $117(33 \%)$ & $114(35 \%)$ & $16(23 \%)$ & \\
\hline CABG and valve & $90(22 \%)$ & $90(25 \%)$ & $68(21 \%)$ & $19(27 \%)$ & \\
\hline \multicolumn{6}{|l|}{ Preoperative medications } \\
\hline ACEI & $164(47 \%)$ & $162(48 \%)$ & $134(45 \%)$ & $27(45 \%)$ & .56 \\
\hline Angiotensin II receptor blockers & $75(21 \%)$ & $64(19 \%)$ & $74(25 \%)$ & $10(17 \%)$ & .74 \\
\hline Aspirin & $288(83 \%)$ & $231(68 \%)$ & $216(72 \%)$ & $40(67 \%)$ & .01 \\
\hline Beta-blockers & $258(74 \%)$ & $239(71 \%)$ & $224(75 \%)$ & $52(87 \%)$ & .18 \\
\hline Statins & $267(77 \%)$ & $238(70 \%)$ & $217(73 \%)$ & $48(80 \%)$ & .68 \\
\hline \multicolumn{6}{|l|}{ Renal function (mean, SD) } \\
\hline Preoperative serum creatinine $(\mathrm{mg} / \mathrm{dL}) \dagger$ & $1.0(0.2)$ & $1.0(0.3)$ & $1.2(0.4)$ & $1.3(0.5)$ & $<.001$ \\
\hline Preoperative eGFR $\left(\mathrm{mL} / \mathrm{min} / 1.73 \mathrm{~m}^{2}\right)$ & $70(17)$ & $71(19)$ & $63(21)$ & $57(22)$ & $<.001$ \\
\hline$<30 \mathrm{~mL} / \min (\mathrm{n}, \%)$ & $4(1 \%)$ & $3(1 \%)$ & $19(6 \%)$ & $10(16 \%)$ & \\
\hline$\geq 30$ and $<45$ & $26(7 \%)$ & $29(10 \%)$ & $50(17 \%)$ & $14(22 \%)$ & \\
\hline$\geq 45$ and $<60$ & $76(21 \%)$ & $66(22 \%)$ & $87(29 \%)$ & $13(20 \%)$ & \\
\hline$\geq 60$ & $252(70 \%)$ & $203(67 \%)$ & $141(47 \%)$ & $27(42 \%)$ & \\
\hline STS bedside score* & $19.2(4.6)$ & $19.9(5.0)$ & $21.8(6.3)$ & $24.1(6.8)$ & $<.001$ \\
\hline
\end{tabular}

ACEI, Angiotensin-converting enzyme inhibitor; SD, standard deviation; STS, Society of Thoracic Surgeons. *Mehta bedside AKI score without chronic lung disease. ${ }^{16}$

$\dagger$ To convert serum creatinine values to $\mathrm{mmol} / \mathrm{L}$, multiply by 88.4 .

preoperative eGFR (Table 1). The use of angiotensinconverting enzyme inhibitors, angiotensin-II receptor blockers, statins, and $\beta$-blockers was not associated with the albuminuria concentrations.

\section{Renal and Nonrenal Outcomes by Urine Albumin to Creatinine Ratio Categories}

During the postoperative period, stage I AKI or worse developed in 409 patients $(35.2 \%)$. The incidence of AKI increased according to the preoperative UACR: 10 $\mathrm{mg} / \mathrm{g}$ or less (26\% incidence), 11 to $29 \mathrm{mg} / \mathrm{g}(35 \%), 30$ to $299 \mathrm{mg} / \mathrm{g}(42 \%)$, or $300 \mathrm{mg} / \mathrm{g}$ or greater $(57 \%)(P$ value for trend $<.001)$. The adjusted relative risk for stage I AKI increased according to the gradient of the UACR, with an approximate doubling in AKI risk for the group with UACR $300 \mathrm{mg} / \mathrm{g}$ or more compared with the group with UACR $10 \mathrm{mg} / \mathrm{g}$ or less (Table 2). Stage II AKI or worse developed in 58 patients $(5.0 \%)$. The incidence of stage II or worse AKI also increased according to the gradient of the UACR; however, after multivariate adjustment the independent association did not meet strict statistical significance (Table 2). Seventeen patients $(1.5 \%)$ required dialysis, of whom 6 died. An additional 13 patients died without requiring dialysis. UACR categories were independently associated with dialysis, length of intensive care unit stay, and length of hospital stay, but not inhospital death (Table 2).

In comparison with other covariates in the final model, all degrees of albuminuria, including microalbuminuria (UACR $10-29 \mathrm{mg} / \mathrm{g}$ ), were comparable or stronger predictor variables for the outcome of stage I AKI than diabetes, hypertension, chronic heart failure, history of myocardial 
TABLE 2. Association of preoperative albuminuria and dipstick proteinuria with outcomes

\begin{tabular}{|c|c|c|c|}
\hline \multirow[b]{2}{*}{ UACR/dipstick categories (n) } & \multicolumn{3}{|c|}{ Stage I AKI or worse } \\
\hline & $\begin{array}{c}\text { AKI } \\
\text { cases }(\mathbf{n}, \%) \\
\end{array}$ & $\begin{array}{c}\text { Unadjusted RR } \\
(\mathbf{9 5} \% \mathbf{C I}) * \\
\end{array}$ & $\begin{array}{c}\text { Adjusted RR } \\
(\mathbf{9 5} \% \mathbf{C I}) \dagger \\
\end{array}$ \\
\hline \multicolumn{4}{|l|}{ Albuminuria } \\
\hline $\mathrm{UACR}<10 \mathrm{mg} / \mathrm{g}(\mathrm{n}=405)$ & $104(26 \%)$ & $1 \ddagger$ & $1 \ddagger$ \\
\hline UACR $10-29 \mathrm{mg} / \mathrm{g}(\mathrm{n}=355)$ & $126(35 \%)$ & $1.36(1.09-1.65)$ & $1.35(1.07-1.66)$ \\
\hline UACR 30-299 mg/g $(\mathrm{n}=329)$ & $139(42 \%)$ & $1.72(1.42-2.03)$ & $1.64(1.33-1.97)$ \\
\hline $\mathrm{UACR} \geq 300 \mathrm{mg} / \mathrm{g}(\mathrm{n}=70)$ & $40(57 \%)$ & $2.36(1.85-2.82)$ & $2.21(1.66-2.73)$ \\
\hline Unadjusted $P$ for trend & $<.0001$ & & \\
\hline Adjusted $P$ for trend & $<.0001$ & & \\
\hline \multicolumn{4}{|l|}{ Dipstick proteinuria } \\
\hline Negative $(n=720)$ & $218(30 \%)$ & $1 \ddagger$ & $1 \ddagger$ \\
\hline Trace $(\mathrm{n}=198)$ & $77(39 \%)$ & $1.28(1.03-1.55)$ & $1.23(0.98-1.52)$ \\
\hline $30-99 \mathrm{mg} / \mathrm{dL}(\mathrm{n}=118)$ & $56(47 \%)$ & $1.59(1.26-1.91)$ & $1.56(1.22-1.90)$ \\
\hline$\geq 100 \mathrm{mg} / \mathrm{dL}(\mathrm{n}=87)$ & $41(47 \%)$ & $1.62(1.26-2.00)$ & $1.42(1.05-1.81)$ \\
\hline Unadjusted $P$ for trend & $<.0001$ & & \\
\hline Adjusted $P$ for trend & .006 & & \\
\hline
\end{tabular}

infarction, and combined $\mathrm{CABG}$ and valve surgery (Table 3).

\section{Renal and Nonrenal Outcomes by Dipstick Proteinuria Categories}

The risk for stage I AKI increased across the dipstick proteinuria categories, although the relationship was not graded $(P$ value for trend $<.006)$, and the adjusted relative risks were slightly less robust than witnessed with the UACR categories (Table 2). Dipstick proteinuria was not associated with the risk of stage II AKI or with nonrenal outcomes after adjustment for covariates.

\section{Risk Discrimination for Urine Albumin to Creatinine Ratio and Dipstick Proteinuria Categories}

Addition of UACR to the clinical model increased the AUC from 0.67 to $0.70(P<.001)$, and dipstick proteinuria increased the AUC for stage I AKI to $0.69(P=.05$, Table 3 ). The addition of UACR or dipstick proteinuria did not increase the AUC significantly for the prediction of stage II AKI (Table 4).

UACR and dipstick proteinuria were able to improve risk classification for AKI. The continuous net reclassification index was $29 \%(P<.001)$ for stage I AKI and 29\% $(P=.01)$ (Figure 1) for stage II AKI with addition of
UACR to the clinical model and $25 \%(P=.001)$ for stage I AKI and $29 \%(P=.03)$ for stage II AKI with addition of dipstick proteinuria to the clinical model (Table 4).

\section{Subgroup and Sensitivity Analysis}

We examined the association of UACR and AKI in the following subgroups: age, diabetes, surgery status, and eGFR categories (eGFR $\geq 60,45-59,30-44$, and $<30$ $\mathrm{mL} / \mathrm{min} / 1.73 \mathrm{~m}^{2}$ ). Surgery status and baseline eGFR were effect modifiers (Table 5). Those with nonelective surgery and UACR $300 \mathrm{mg} / \mathrm{g}$ or greater $(\geq 33.9 \mathrm{mg} / \mathrm{mol})$ had a lower relative risk than those with elective surgery and the same albuminuria group. Higher levels of UACR were associated with a stepwise increase in the risk for postoperative AKI in those with eGFR 45 to $59 \mathrm{~mL} / \mathrm{min} /$ $1.73 \mathrm{~m}^{2}$ and $60 \mathrm{~mL} / \mathrm{min} / 1.73 \mathrm{~m}^{2}$ or greater, but were not associated with increased risk in eGFR 30 to $44 \mathrm{~mL} / \mathrm{min} /$ $1.73 \mathrm{~m}^{2}$ and less than $30 \mathrm{~mL} / \mathrm{min} / 1.73 \mathrm{~m}^{2}$ (Table 5). A similar trend was observed with the dipstick proteinuria categories (data not shown).

\section{DISCUSSION}

AKI is a major postoperative complication of cardiac surgery. Even a mild increase in creatinine as small as $0.3 \mathrm{mg} / \mathrm{dL}(26.5 \mu \mathrm{mol} / \mathrm{L})$ (AKI stage I) in this setting is 
TABLE 2. Continued

\begin{tabular}{|c|c|c|c|c|c|}
\hline \multicolumn{3}{|c|}{ Stage II AKI } & \multicolumn{3}{|c|}{ Other outcomes } \\
\hline $\begin{array}{l}\text { AKI cases } \\
(\mathbf{n}, \%) \\
\end{array}$ & $\begin{array}{c}\text { Unadjusted RR } \\
(\mathbf{9 5} \% \mathbf{C I}) \\
\end{array}$ & $\begin{array}{c}\text { Adjusted RR } \\
(\mathbf{9 5} \% \mathbf{C I}) \dagger \\
\end{array}$ & $\begin{array}{c}\text { In- hospital } \\
\text { dialysis }(\mathbf{n}, \%)\end{array}$ & $\begin{array}{l}\text { Length of stay in ICU, mean } \\
\text { (SD) median [IQR] }\end{array}$ & $\begin{array}{l}\text { Length of stay in hospital, } \\
\text { mean (SD) median [IQR] }\end{array}$ \\
\hline \multirow{2}{*}{$13(3.2 \%)$} & $1 \ddagger$ & $1 \ddagger$ & $4(1.0 \%)$ & $3.0(7.5)$ & $7.7(8.7)$ \\
\hline & & & & $2[1-2]$ & $6[5-8]$ \\
\hline \multirow[t]{2}{*}{$18(5.1 \%)$} & $1.50(0.74-2.98)$ & $1.44(0.70-2.91)$ & $3(0.9 \%)$ & $3.3(10.6)$ & $9.1(13.9)$ \\
\hline & & & & $2[1-3]$ & 6 [5-9] \\
\hline \multirow[t]{2}{*}{$21(6.4 \%)$} & $2.11(1.07-4.03)$ & $1.94(0.95-3.86)$ & $5(1.5 \%)$ & $3.1(4.4)$ & $8.2(6.5)$ \\
\hline & & & & $2[1-4]$ & 7 [5-9] \\
\hline \multirow[t]{2}{*}{$6(8.6 \%)$} & $3.01(1.16-7.11)$ & $2.59(0.93-6.58)$ & $5(7.1 \%)$ & $7.1(14.7)$ & $12.4(14.9)$ \\
\hline & & & & $2[1-6]$ & 7 [6-11] \\
\hline .0154 & & & .009 & $<.0001$ & $<.0001$ \\
\hline .07 & & & .0009 & .015 & .019 \\
\hline \multirow[t]{2}{*}{$30(4.2 \%)$} & $1 \ddagger$ & $1 \ddagger$ & $7(1.0 \%)$ & $2.9(5.6)$ & $8.0(8.3)$ \\
\hline & & & & $2[1-3]$ & $6[5-8]$ \\
\hline \multirow[t]{2}{*}{$15(7.6 \%)$} & $1.93(1.05-3.45)$ & $1.75(0.93-3.19)$ & $3(1.5 \%)$ & $4.2(14.8)$ & 9.5 (16.9) \\
\hline & & & & $2[1-3]$ & $6[5-8]$ \\
\hline \multirow[t]{2}{*}{$6(5.1 \%)$} & $1.22(0.51-2.79)$ & $1.06(0.43-2.51)$ & $2(1.7 \%)$ & $3.5(7.8)$ & $9.2(9.5)$ \\
\hline & & & & $2[1-3]$ & 7 [5-9] \\
\hline \multirow[t]{2}{*}{$7(8.1 \%)$} & $2.09(0.92-4.44)$ & $1.86(0.79-4.09)$ & $5(5.8 \%)$ & $5.3(11.7)$ & $10.1(11.7)$ \\
\hline & & & & $2[1-4]$ & 7 [5-10] \\
\hline .0872 & & & .003 & .0004 & .0008 \\
\hline .53 & & & .012 & .24 & .30 \\
\hline
\end{tabular}

associated with increased morbidity and mortality. ${ }^{19}$ Our study demonstrates that preoperative albuminuria (UACR) is independently associated with the development of AKI even after consideration of several important preoperative characteristics. Furthermore, dipstick proteinuria is also an independent predictor for the development of stage I AKI. In addition, preoperative UACR is independently associated with in-hospital dialysis, intensive care unit length of stay, and in-hospital length of stay. Both UACR and dipstick proteinuria have better prognostic ability for AKI in patients with eGFR $45 \mathrm{~mL} / \mathrm{min} / 1.73 \mathrm{~m}^{2}$ or greater than in patients with eGFR $45 \mathrm{~mL} / \mathrm{min} / 1.73 \mathrm{~m}^{2}$ or less and those undergoing elective surgery.

Our study builds on the results of Huang and colleagues,${ }^{10}$ demonstrating that preoperative proteinuria is an independent risk factor for the development of cardiac surgery-associated AKI. In their study involving patients undergoing cardiac surgery, urine dipstick defined as mild (trace to $1+$ ) had an adjusted odds ratio of 1.66 for the development of AKI (95\% confidence interval, 1.09-2.52), and heavy proteinuria ( $2+$ to $4+$ ) had an adjusted odds ratio of 2.30 (95\% confidence interval, 1.35-3.90). Our study extends their observations by incorporating UACR for categorization and analyses. Our results are similar to the nonsurgical setting in which Grams and colleagues ${ }^{7}$ demonstrated that UACR is associated with AKI in a graded
TABLE 3. Full multivariate models for stage I and II acute kidney injury

\begin{tabular}{|c|c|c|}
\hline $\begin{array}{l}\text { Multivariable adjusted } \\
\text { RR }(95 \% \text { CI })\end{array}$ & Stage I AKI & Stage II AKI \\
\hline \multicolumn{3}{|l|}{ UACR } \\
\hline$<10 \mathrm{mg} / \mathrm{g}$ & 1 & 1 \\
\hline $10-29$ & $1.35(1.07-1.66)$ & $1.44(0.7-2.91)$ \\
\hline 30-299 & $1.64(1.33-1.97)$ & $1.94(0.95-3.86)$ \\
\hline$\geq 300$ & $2.21(1.66-2.73)$ & $2.59(0.93-6.58)$ \\
\hline Age (per year) & $1.003(0.993-1.013)$ & $0.993(0.964-1.024)$ \\
\hline Female & $0.75(0.60-0.92)$ & $0.91(0.52-1.6)$ \\
\hline White & $1.1(0.76-1.49)$ & $0.98(0.36-2.48)$ \\
\hline eGFR (per $\mathrm{mL} / \mathrm{min} / 1.73 \mathrm{~m}^{2}$ ) & $0.993(0.988-0.998)$ & $0.995(0.981-1.009)$ \\
\hline Diabetes & $1.16(0.96-1.37)$ & $1.10(0.63-1.92)$ \\
\hline Elective & $0.60(0.46-0.76)$ & $0.55(0.29-1.05)$ \\
\hline Hypertension & $1.20(0.94-1.48)$ & $1.70(0.75-3.70)$ \\
\hline Chronic heart failure & $1.28(1.04-1.53)$ & $1.59(0.86-2.88)$ \\
\hline $\begin{array}{l}\text { Cardiac catheterization in } \\
\text { past } 48 \mathrm{~h}\end{array}$ & $1.00(0.99-1.01)$ & $1.00(1.00-1.00)$ \\
\hline Myocardial infarction & $0.95(0.76-1.16)$ & $1.14(0.61-2.1)$ \\
\hline \multicolumn{3}{|l|}{ Type of surgery } \\
\hline Valve & 1 & 1 \\
\hline CABG & $0.86(0.66-1.09)$ & $0.60(0.28-1.27)$ \\
\hline CABG and valve & $1.11(0.88-1.34)$ & $1.52(0.78-2.87)$ \\
\hline
\end{tabular}

$C I$, Confidence interval; $S D$, standard deviation. 
TABLE 4. Risk discrimination and continuous net reclassification index for stage I and II acute kidney injury by urine albumin to creatinine ratio and urine dipstick measurements

\begin{tabular}{lcc}
\hline & Stage I AKI & Stage II AKI \\
\hline Area under the ROC curve (SE) & & \\
$\quad$ Albuminuria & $0.60(0.02)$ & $0.59(0.04)$ \\
Clinical model & $0.67(0.02)$ & $0.72(0.04)$ \\
Clinical model + albuminuria & $0.70(0.02)$ & $0.73(0.04)$ \\
$P$ value* & .006 & .50 \\
Dipstick & $0.57(0.02)$ & $0.57(0.04)$ \\
Clinical model & $0.67(0.02)$ & $0.73(0.04)$ \\
Clinical model+ dipstick & $0.69(0.02)$ & $0.73(0.04)$ \\
$P$ value $\dagger$ & .027 & .70 \\
Continuous Net reclassification index $(\mathrm{SE})$ & \\
Albuminuria & $0.29(0.06)$ & $0.29(0.14)$ \\
$P$ value & $<.0001$ & .031 \\
Dipstick & $0.25(0.06)$ & $0.29(0.14)$ \\
$P$ value & $<.0001$ & .035 \\
\hline
\end{tabular}

Clinical model includes age (per year), sex, white race, preoperative eGFR (per mL/ $\min / 1.73 \mathrm{~m}^{2}$ ), diabetes, elective surgery, hypertension, chronic heart failure, cardiac catheterization in past $48 \mathrm{~h}$, myocardial infarction, type of surgery, and center. $R O C$, Receiver operating curve; $S E$, standard error. $* P$ value comparing the addition of albuminuria with the clinical model. $\dagger P$ value comparing the addition of dipstick with the clinical model.

fashion in a community-based population. We confirmed that low-grade albuminuria (UACR $<30 \mathrm{mg} / \mathrm{g}$ ), which generally is not considered pathologic, was independently associated with the risk for AKI.
Several clinical risk-scoring systems have been developed and validated to predict the risk of AKI in cardiac surgery. The majority consider severe AKI as the end point (requiring acute renal replacement therapy). ${ }^{12,13}$ However, a few studies developed models for predicting milder forms of AKI. ${ }^{20,21}$ Regardless, all the clinical risk scoring systems, except one, ${ }^{21}$ solely used preoperative serum creatinine or glomerular filtration rate (GFR) to define chronic kidney disease. None of the studies examined the added value of albuminuria or proteinuria to predict AKI in cardiac surgery. In this multicenter cohort study of patients undergoing cardiac surgery, we found that both preoperative UACR and dipstick proteinuria add to preoperative risk stratification for AKI.

These risk-assessment tools are used both to allow individual patients and surgeons to balance the risks and benefits of cardiac surgery and to monitor the quality of care and outcomes of cardiac surgery. Cardiac surgery outcomes are widely monitored; thus, even mild improvements to help risk adjust for adverse outcomes may have great clinical and research importance by choosing alternative procedures (eg, percutaneous coronary revascularization or valve repair) and selection of a high-risk cohort for enrollment into randomized controlled trials. Therefore, if preoperative proteinuria can be validated further as a relevant marker for improving risk assessment for AKI or other adverse outcomes after cardiac surgery, then
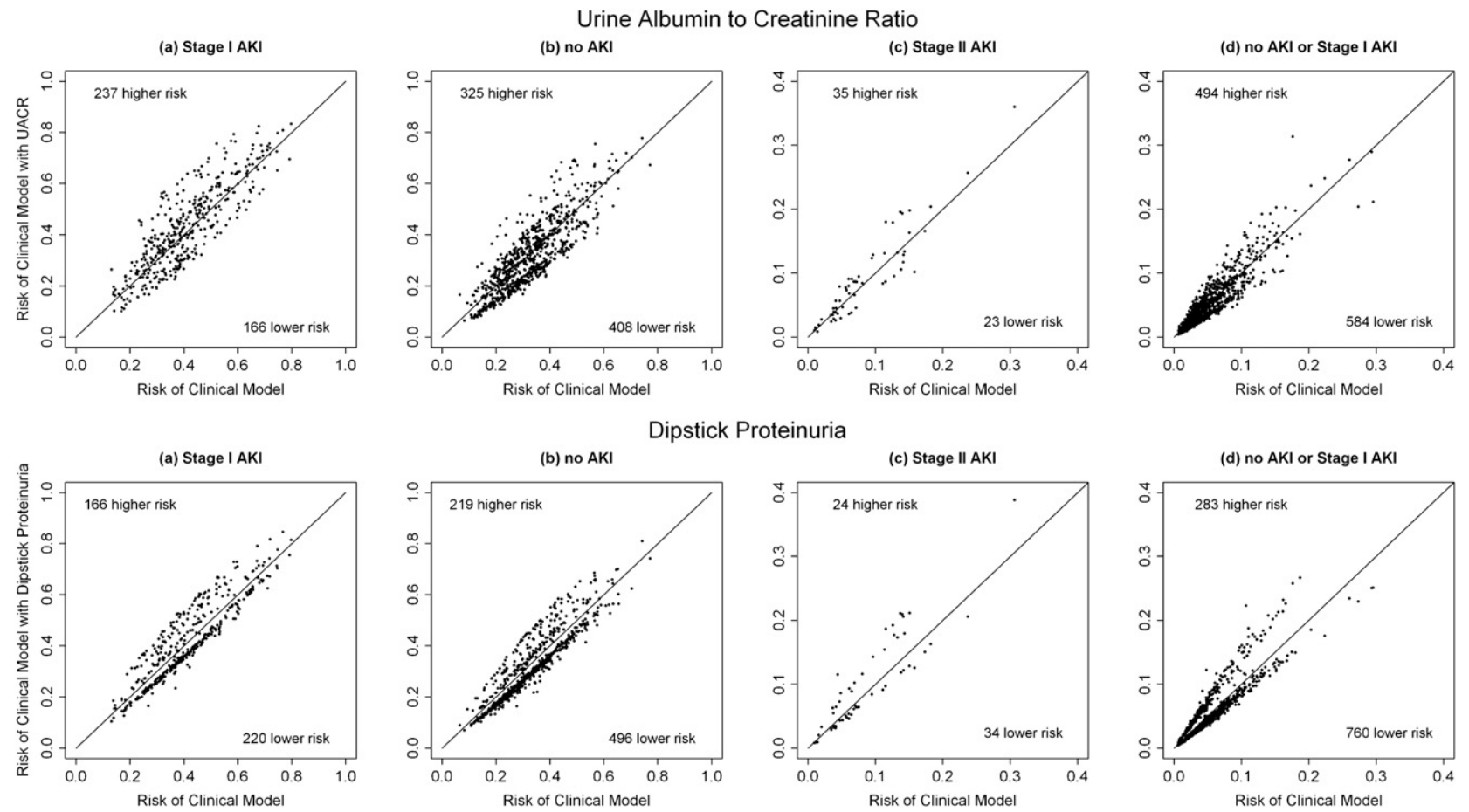

FIGURE 1. Predicted risk of clinical model with and without UACR. Plots show the predicted risk for (A) AKI and (B) no AKI for stage I AKI and (C) stage II AKI and (D) no AKI or stage I AKI for stage II AKI according to the clinical model (x-axis) and to the model with preoperative UACR or dipstick proteinuria added (y-axis). The diagonal line indicates that for points above this line, the predicted risk of stage I AKI is higher in the new model and that for points below this line, the predicted risk is lower. AKI, Acute kidney injury. 
TABLE 5. Relative risks ( $95 \%$ confidence interval) of urine albumin to creatinine ratio for acute kidney injury by prespecified subgroups

\begin{tabular}{|c|c|c|c|c|c|}
\hline Variable, (n) & $\begin{array}{c}\text { UACR }<10 \mathrm{mg} / \mathrm{g} \\
\text { n AKI } / \text { total }(\%) \\
\text { RR }(95 \% \text { CI } \dagger \dagger\end{array}$ & $\begin{array}{c}\text { UACR 11-29 mg/g } \\
\text { n AKI/total (\%) } \\
\text { RR }(95 \% \text { CI }) \\
\end{array}$ & $\begin{array}{c}\frac{\text { UACR 30-299 mg/g }}{\text { n AKI/total (\%) }} \\
\text { RR }(95 \% \text { CI }) \\
\end{array}$ & $\begin{array}{c}\text { UACR }>300 \mathrm{mg} / \mathrm{g} \\
\text { n AKI } / \text { total }(\%) \\
\text { RR }(95 \% \text { CI }) \\
\end{array}$ & $P$ for trend \\
\hline \multicolumn{6}{|l|}{ Age, y } \\
\hline \multirow[t]{2}{*}{$<65(250)$} & $21 / 97(22 \%)$ & $30 / 73(41 \%)$ & $26 / 61(43 \%)$ & $12 / 19(63 \%)$ & .008 \\
\hline & 1 & $1.8(1.1-2.6)$ & $2.0(1.2-2.8)$ & $3.0(1.8-3.9)$ & \\
\hline \multirow[t]{2}{*}{$65-75(440)$} & $39 / 164(24 \%)$ & $44 / 134(33 \%)$ & $50 / 118(42 \%)$ & $16 / 24(67 \%)$ & $<.001$ \\
\hline & 1 & $1.4(0.9-1.9)$ & $1.9(1.3-2.4)$ & $3.0(2.0-3.6)$ & \\
\hline \multirow[t]{2}{*}{$75-85(410)$} & $42 / 133(32 \%)$ & $46 / 134(34 \%)$ & $50 / 120(42 \%)$ & $12 / 23(52 \%)$ & .14 \\
\hline & 1 & $1.1(0.7-1.5)$ & $1.4(0.9-1.8)$ & $1.7(1.0-2.3)$ & \\
\hline \multirow[t]{2}{*}{$>85(59)$} & $2 / 11(18 \%)$ & $6 / 14(43 \%)$ & $13 / 30(43 \%)$ & $0 / 0(0 \%)$ & .22 \\
\hline & 1 & $2.3(0.5-4.6)$ & $2.4(0.6-4.5)$ & & \\
\hline \multicolumn{6}{|l|}{ Diabetes } \\
\hline \multirow[t]{2}{*}{ Yes (219) } & $41 / 141(29 \%)$ & $47 / 137(34 \%)$ & $76 / 155(49 \%)$ & $26 / 46(57 \%)$ & $<.001$ \\
\hline & 1 & $1.1(0.7-1.5)$ & $1.70(1.3-2.1)$ & $2.0(1.4-2.5)$ & \\
\hline \multirow[t]{2}{*}{ No (461) } & $63 / 264(24 \%)$ & $79 / 218(36 \%)$ & $63 / 174(36 \%)$ & $14 / 24(58 \%)$ & .001 \\
\hline & 1 & $1.5(1.1-1.9)$ & $1.63(1.2-2.0)$ & $2.5(1.6-3.3)$ & \\
\hline \multicolumn{6}{|l|}{ Surgery status* } \\
\hline \multirow[t]{2}{*}{ Elective (920) } & $64 / 306(21 \%)$ & $92 / 295(31 \%)$ & $105 / 265(40 \%)$ & $33 / 54(61 \%)$ & $<.001$ \\
\hline & 1 & $1.4(1.0-1.78)$ & $1.3(0.9-1.7)$ & $1.2(0.6-1.8)$ & \\
\hline \multirow[t]{2}{*}{ Nonelective (239) } & $40 / 99(40 \%)$ & $34 / 60(57 \%)$ & $34 / 64(53 \%)$ & $7 / 16(44 \%)$ & .21 \\
\hline & 1 & $1.4(1.1-1.8)$ & $2.0(1.6-2.4)$ & $3.0(2.3-3.6)$ & \\
\hline \multicolumn{6}{|l|}{$\begin{array}{l}\mathrm{eGFR} \ddagger \\
\qquad\left(\mathrm{mL} / \mathrm{min} / 1.73 \mathrm{~m}^{2}\right)\end{array}$} \\
\hline \multirow[t]{2}{*}{$<30(36)$} & $2 / 4(50 \%)$ & $3 / 3(100 \%)$ & $8 / 19(42 \%)$ & $7 / 10(70 \%)$ & .22 \\
\hline & 1 & & $0.8(0.1-1.8)$ & $1.4(0.3-1.9)$ & \\
\hline \multirow[t]{2}{*}{ 30-44 (119) } & $10 / 26(38 \%)$ & $14 / 29(48 \%)$ & $27 / 50(54 \%)$ & $6 / 14(43 \%)$ & .61 \\
\hline & 1 & $1.3(0.6-1.9)$ & $1.4(0.8-2.0)$ & $1.1(0.4-1.9)$ & \\
\hline \multirow[t]{2}{*}{$45-59(242)$} & $20 / 76(26 \%)$ & $23 / 66(35 \%)$ & $42 / 87(48 \%)$ & $9 / 13(69 \%)$ & .003 \\
\hline & 1 & $1.3(0.8-2.0)$ & $2.0(1.3-2.6)$ & $2.8(1.6-3.5)$ & \\
\hline \multirow[t]{2}{*}{$\geq 60(762)$} & $72 / 299(24 \%)$ & $86 / 257(33 \%)$ & $62 / 173(36 \%)$ & $18 / 33(55 \%)$ & .005 \\
\hline & 1 & $1.3(1.0-1.7)$ & $1.6(1.2-2.0)$ & $2.5(1.7-3.1)$ & \\
\hline
\end{tabular}

$* P$ for interaction $<.001$ for elective vs nonelective surgery. $\dagger$ Referent. $\ddagger P$ for interaction $=.01$ for eGFR $\geq 45 \mathrm{vs}<45 \mathrm{~mL} / \mathrm{min} / 1.73 \mathrm{~m}^{2}$. Site is included as random effect.

it could be of value to individual patients, clinicians, hospitals, and trialists.

It has been postulated that proteinuria represents endothelial dysfunction or may injure the kidney itself. There is a body of evidence that describes proteinuria as toxic to the tubules. This can result in significant tubulointerstitial injury and progression of renal disease independently of the cause of proteinuria in chronic kidney disease. Filtered albumin when taken up by renal tubular cells via receptormediated endocytosis can trigger expression of a series of proinflammatory molecules, such as monocyte chemotactic protein-1, osteopontin, regulated on activation normal $\mathrm{T}$ cell expressed and secreted, and endothelin- $1 .{ }^{10}$ Also, low molecular weight proteinuria can exacerbate acute ischemic injury in experimental animals. ${ }^{22}$ Patients with albuminuria may have some degree of altered functional renal reserve because of the above mentioned factors and are more prone to ischemic injury during cardiac surgery. ${ }^{23}$

We found effect modification by 2 clinical variables: surgery status and preoperative eGFR. Specifically, the relationship between the degree of preoperative proteinuria and the risk for AKI was stronger in those undergoing elective surgery and those who had higher preoperative eGFR but was weak or abolished in those undergoing urgent surgery and those with eGFR less than $45 \mathrm{~mL} / \mathrm{min} / \mathrm{m}^{2}$. These findings are not surprising. In patients who are already at higher risk for AKI (urgent surgery and profoundly decreased baseline eGFR), it is unlikely that additional parameters will provide more information for the risk of outcomes. However, in patients with lower preoperative risk, a measure of kidney injury (eg, proteinuria) may provide additional benefit for risk stratification. For example, in those with GFR greater than 60 and no albuminuria, the rate of AKI was $24 \%$. In contrast, the rate of AKI in those with GFR 30 to 44 was $38 \%$. Thus, because the background or baseline risk of AKI is already higher in those with low GFR, it is more difficult to demonstrate higher risk in association with another predictor variable, in this case albuminuria. These findings are similar to those of Tonelli and colleagues, ${ }^{11}$ who showed that the value of 
albuminuria to risk-stratify for the outcomes of end-stage renal disease and all-cause mortality was greatest in those with higher baseline eGFR.

The strengths of this study are that it is a multicenter cohort study involving 6 large academic centers in North America and representative of contemporaneous surgical practice. Furthermore, unlike in previous studies, ${ }^{8,9,10}$ proteinuria was measured by both UACR and dipstick at the bedside; thus, we were able to compare the 2 methodologies of assessment of proteinuria with the outcomes. However, there are some limitations to our study. The majority of the patients in our cohort experienced only mild AKI (AKIN stage I). The number of patients with stage II AKI (or worse) was lower, which may have limited our ability to observe a stable independent relationship between albuminuria and more severe AKI. However, the distribution of severity of AKI reflects the current epidemiology of AKI in cardiac surgery in the modern era in North America. In addition, despite the multicenter design of our study, two thirds of participants were male and more than $90 \%$ were white. The ability of the models to correctly classify patients as AKI or non-AKI using preoperative variables was only modest, with an AUC of 0.7. Thus, additional factors, such as intraoperative and postoperative events, also influence the ultimate risk for AKI. Finally, the amount of proteinuria by dipstick can be influenced by urine concentration.

\section{CONCLUSIONS}

Our results indicate that preoperative proteinuria, by both UACR and urine dipstick, is an independent predictor for the risk of developing stage I AKI in cardiac surgery. UACR is also an independent predictor of other important outcomes, including dialysis and length of stay. However, with consideration of the cost differential between the 2 tests ( $\sim 40$ cents per patient for dipstick and $\$ 130$ per patient for UACR), dipstick proteinuria may be a more costeffective method to screen patients before surgery because it still improved risk classification by $24 \%$. This implies that the number needed to screen via UACR to correctly classify 1 patient before surgery is 14 , at a total cost of $\$ 1820$. Future studies will need to determine whether the additional precision at the expense of increased costs is worth pursuing and then translates into improved clinical outcomes. We propose that these widely available tests that can be performed at the bedside can be used as an aid in assessing risk for poor outcomes in patients undergoing cardiac surgery.

The authors thank the nursing and support staff of the preadmission clinic, anesthesia units, and cardiac care units at all the participating sites.

\section{References}

1. Loef BG, Epema AH, Smilde TD, Henning RH, Ebels T, Navis G, et al. Immediate postoperative renal function deterioration in cardiac surgical patients predicts in-hospital mortality and long-term survival. J Am Soc Nephrol. 2005;16: 195-200.

2. Ishani A, Nelson D, Clothier B, Schult T, Nugent S, Greer N, et al. The magnitude of acute serum creatinine increase after cardiac surgery and the risk of chronic kidney disease, progression of kidney disease, and death. Arch Intern Med. 2011;14:226-33.

3. Higgins TL, Estafanous FG, Loop FD, Beck GJ, Blum JM, Paranandi L. Stratification of morbidity and mortality outcome by preoperative risk factors in coronary artery bypass patients. A clinical severity score. JAMA. 1992;267: 2344-8.

4. Lombardi R, Ferreiro A. Risk factors profile for acute kidney injury after cardiac surgery is different according to the level of baseline renal function. Ren Fail. 2008;30:155-60.

5. Hallan SI, Ritz E, Lydersen S, Romundstad S, Kvenild K, Orth SR. Combining GFR and albuminuria to classify CKD improves prediction of ESRD. J Am Soc Nephrol. 2009;20:1069-77.

6. Levey AS, Atkins R, Coresh J, Cohen EP, Collins AJ, Eckardt KU, et al. Chronic kidney disease as a global public health problem: approaches and initiativesa position statement from Kidney Disease Improving Global Outcomes. Kidney Int. 2007;72:247-59.

7. Grams ME, Astor BC, Bash LD, Matsushita K, Wang Y, Coresh J. Albuminuria and estimated glomerular filtration rate independently associate with acute kidney injury. J Am Soc Nephrol. 2010;21:1757-64.

8. Hsu CY, Ordonez JD, Chertow GM, Fan D, McCulloch CE, Go AS. The risk of acute renal failure in patients with chronic kidney disease. Kidney Int. 2008;74: 101-7.

9. James MT, Hemmelgarn BR, Wiebe N, Pannu N, Manns BJ, Klarenbach SW, et al. Glomerular filtration rate, proteinuria, and the incidence and consequences of acute kidney injury: a cohort study. Lancet. 2010;376:2096-103.

10. Huang TM, Wu VC, Young GH, Lin YF, Shiao CC, Wu PC, et al. Preoperative proteinuria predicts adverse renal outcomes after coronary artery bypass grafting. J Am Soc Nephrol. 2011;22:156-63.

11. Tonelli M, Muntner P, Lloyd A, Manns BJ, James MT, Klarenbach S, et al. Using proteinuria and estimated glomerular filtration rate to classify risk in patients with chronic kidney disease: a cohort study. Ann Intern Med. 2011;154:12-21.

12. Chertow GM, Lazarus JM, Christiansen CL, Cook EF, Hammermeister KE, Grover F, et al. Preoperative renal risk stratification. Circulation. 1997;95: 878-84.

13. Thakar CV, Arrigain S, Worley S, Yared JP, Paganini EP. A clinical score to predict acute renal failure after cardiac surgery. J Am Soc Nephrol. 2005;16:162-8.

14. Zhang J, Yu KF. What's the relative risk? A method of correcting the odds ratio in cohort studies of common outcomes. JAMA. 1998;280:1690-1.

15. Levey AS, Stevens LA, Schmid CH, Zhang YL, Castro AF 3rd, Feldman HI, et al. A new equation to estimate glomerular filtration rate. Ann Intern Med. 2009;150: 604-12.

16. Mehta RH, Grab JD, O'Brien SM, Bridges CR, Gammie JS, Haan CK, et al. Bedside tool for predicting the risk of postoperative dialysis in patients undergoing cardiac surgery. Circulation. 2006;114:2208-16; quiz.

17. DeLong ER, DeLong DM, Clarke-Pearson DL. Comparing the areas under two or more correlated receiver operating characteristic curves: a nonparametric approach. Biometrics. 1988;44:837-45.

18. Pencina MJ, Sr D'Agostino RB, Steyerberg EW. Extensions of net reclassification improvement calculations to measure usefulness of new biomarkers. Stat Med. 2011;30:11-21.

19. Lassnigg A, Schmidlin D, Mouhieddine M, Bachmann LM, Druml W, Bauer P, et al. Minimal changes of serum creatinine predict prognosis in patients after cardiothoracic surgery: a prospective cohort study. J Am Soc Nephrol. 2004;15: 1597-605.

20. Palomba H, de Castro I, Neto AL, Lage S, Yu L. Acute kidney injury prediction following elective cardiac surgery: AKICS Score. Kidney Int. 2007;72:624-31.

21. Brown JR, Cochran RP, Leavitt BJ, Dacey LJ, Ross CS, MacKenzie TA, et al. Multivariable prediction of renal insufficiency developing after cardiac surgery. Circulation. 2007;116:I139-43.

22. Zager RA, Teubner EJ, Adler S. Low molecular weight proteinuria exacerbates experimental ischemic renal injury. Lab Invest. 1987;56:180-8.

23. Glassock RJ. Is the presence of microalbuminuria a relevant marker of kidney disease? Curr Hypertens Rep. 2010;12:364-8. 